\title{
Influence of the Deviation of Rolled Piece on Its Asymmetric Degree of Profile in Hot Rolling
}

\author{
Xiaojun Chai ${ }^{1, a}$, Hongbo $\mathrm{Li}^{1, b^{*}}$, Jie Zhang ${ }^{1, \mathrm{c}}$, Yizhong Zhou ${ }^{2, \mathrm{~d}}$, Weidong $\mathrm{Hu}^{2, \mathrm{e}}$, \\ Pengwu Zhang ${ }^{2, f}$ \\ ${ }^{1}$ School of Mechanical Engineering, University of Science and Technology Beijing, Beijing 100083, \\ China \\ ${ }^{2}$ Wuhan Iron and Steel Co. Ltd., Wuhan 430083, China

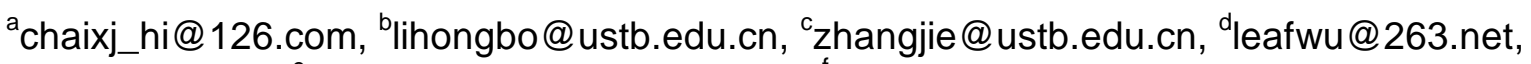 \\ ewuhanhuweidong@sina.com, pengwu2008@163.com
}

Keywords: Hot Rolling; Deviation; Asymmetric Profile; Influence Function Method

Abstract. Asymmetric flatness occurred on the products of a $2250 \mathrm{~mm}$ hot rolling line when they were rolled in a cold mill. The production data reflected that these products deviated much in hot rolling. Because of the large thickness, rolled pieces show asymmetric profile instead of asymmetric flatness under asymmetric rolling condition. An index is established to express the asymmetric character of profile efficiently. The tilt variables of rollers are introduced to deflection model of rollers based on influence function method to build an asymmetric deflection model to analyze the influence of deviation on the asymmetric index of rolled piece profile when pieces of different width and height are rolled as well as at different stands. This is of great importance for controlling deviation of rolled piece to ensure its shape quality.

\section{Introduction}

With development of metal forming theory and wide application of advanced controlling strategy and equipments in rolling process, the symmetric shape quality was improved remarkably[1], while the asymmetric flatness still occurred frequently. Strip steels of a $2250 \mathrm{~mm}$ hot rolling line showed asymmetric flatness problem when rolled in cold mills, increasing judgement-changing rate and rejection rate, which had a direct relation with the asymmetric profile formed in hot mill. Production data analysis indicated that these productions deviated much in hot rolling. In industrial production, there is a reciprocal causation relationship between deviation of rolled piece and its asymmetric profile. Domestic and foreign scholars investigated the relationship at different angles, including the transforming relationship from the wedge of rolled piece to its deviation via different models[2,3], the factors causing deviation[4,5], the deviation controlling strategy[6] and the influence on flatness of deviation[7]. However, the present research results are not enough to give a definite priority relationship between wedge and deviation to be applied in industry. Because the asymmetric profile in rolling process has low measurability while the deviation of rolled piece can be limited by the side guide, it is meaningful for improving strip quality to investigate the influence on the profile of deviation of rolled piece unidirectionally. In addition, many scholars use wedge to characterize the asymmetric profile, which cannot fully reflect the asymmetric profile. According to the practical profile, an index is established in this paper. And an asymmetric deflection model of rollers is built to investigate the influence on the profile of deviation, which provides an important reference for the quality controlling of strip steel of different specification.

\section{Asymmetric profile}

Because of the large thickness, the hot strips usually show asymmetric profile instead of asymmetric flatness problem. A new asymmetric index is necessary to make up the defects of wedge in characterizing an asymmetric profile for it only denotes the thickness difference of two specified locations. 
The practical profile of rolled piece measured at the exit side of finishing mill as well as its quartic fitting curve are shown in Fig.1. The expression for curve is Eq.1.

$$
f(x)=A_{0}+A_{1} x+A_{2} x^{2}+A_{3} x^{3}+A_{4} x^{4} .
$$

The polynomial can be divided into two parts: the symmetric part and the asymmetric part[8]. The latter includes $\mathrm{A}_{1} \mathrm{x}, \mathrm{A}_{3} \mathrm{x}^{3}$, used to express the profile asymmetry. In order to contain more thickness distribution information in the new asymmetric index, the area difference $\Delta S$ enclosed by the fitting curve and coordinate axis on both sides are calculated via integration of thickness curve along the width direction.

There are two traditional asymmetric indexes: wedge $\mathrm{W}_{1}$ and three-order wedge $\mathrm{W}_{\mathrm{p}}$, which denote the thickness difference between $-\mathrm{B} / 2$ and $\mathrm{B} / 2$ and thickness difference between $-\mathrm{B} / 4$ and $\mathrm{B} / 4$ respectively. The former is equal to wedge used in production spot. The area difference $\Delta \mathrm{S}$ can be expressed with $\mathrm{W}_{1}$ and $\mathrm{W}_{\mathrm{p}}$. In order to express the asymmetry degree per unit width, $\Delta \mathrm{S}$ is divided by $B$ to raise a new asymmetric index-profile asymmetry degree $A_{p}$, which is shown in Eq.2.

$$
A_{p}=\frac{\Delta S}{B}=\frac{B\left(\frac{1}{12} W_{l}+\frac{1}{3} W_{p}\right)}{B}=\frac{1}{12} W_{l}+\frac{1}{3} W_{p} .
$$

The wedge $\mathrm{W}_{\mathrm{l}}$, three-order wedge $\mathrm{W}_{\mathrm{p}}$, and profile asymmetry degree $\mathrm{A}_{\mathrm{p}}$ of three arbitrary rolled pieces got from the production spot are calculated, and the results are shown in Table. 1, from which it can be seen that $\mathrm{W}_{1}$ and $\mathrm{W}_{\mathrm{p}}$ are independent and the rolled piece which has larger wedge unnecessarily has larger profile asymmetry degree. Profile asymmetry degree can fully reflect the asymmetric profile with a simpler form, which is of great importance for the expression and control of the profile.

Table. 1 The Comparision of the new and traditional asymmetric indexes

\begin{tabular}{cccc}
\hline rolled piece & $\mathrm{W}_{1}[\mu \mathrm{m}]$ & $\mathrm{W}_{\mathrm{p}}[\mu \mathrm{m}]$ & $\mathrm{A}_{\mathrm{p}}[\mu \mathrm{m}]$ \\
\hline $1 \#$ & -18.34 & -14.09 & -5.97 \\
$2 \#$ & -20.94 & -0.43 & -1.87 \\
$3 \#$ & -4.51 & -10.69 & -3.94 \\
\hline
\end{tabular}

\section{Asymmetric deflection model of rollers}

The deflection model of rollers is built based on the influence function method. According to concept of influence function in mathematical equation, the deflection of element caused by the unit force imposed on other element can be added to calculate the total deflection of each element of rollers.

The deflection model contains top and bottom backup rollers, top and bottom work rollers and rolled piece. Half of the model is built because of its symmetry, which is shown in Fig.2. The backup roller, work roller and rolled piece are discretized into $2 n_{b}, 2 n_{w}, 2 n_{s}$ elements respectively. $P_{1}, P_{2}$ denote the indenter force on both sides of the mill; $F_{1}, F_{2}$ denote the bending force imposed on the both ends of work roller; $q$ denotes the lateral distribution of contact pressure between rollers; $p$ denotes the lateral distribution of rolling pressure. Deviation of rolled piece leads to the asymmetric rolling condition, and then leads to the rotation of rollers. $\alpha, \beta$ denote the rotation angle of work rollers and backup rollers respectively; $d$ denotes the change of number of elements on both sides caused by deviation.

The backup roller is tilted to adjust the shape of rolled piece in production spot, and the tilting angle is denoted by $\beta_{0}$. Under the asymmetric rolling condition, the displacement of the backup rollers on both ends is different, leading to a rotation angle increment denoted by $\Delta \beta$, which can be calculated by displacement difference equation of two ends of the backup roller. The rotation angle of backup roller $\beta$ is equal to sum of $\beta_{0}$ and $\Delta \beta$. The rotation angle of work roller $\alpha$ is derived from the moment equilibrium equation. 


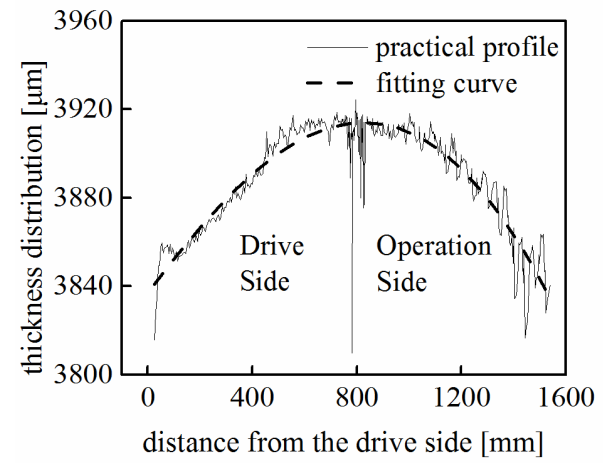

Fig.1. The practical profile and the fitting curve

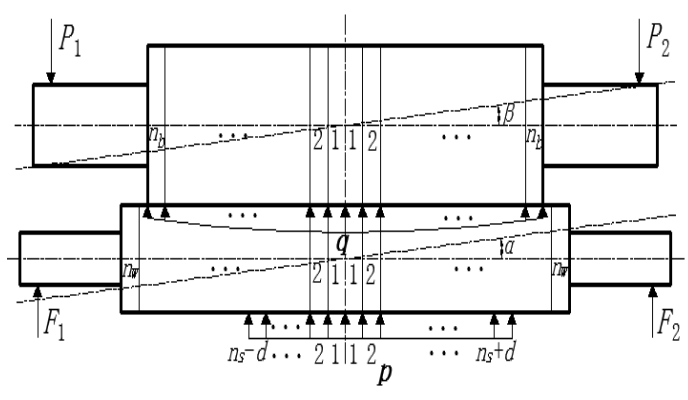

Fig.2. Half of the deflection model

\section{Influence on profile of deviation of rolled piece and production control}

The hot rolling process at F1, F4 and F7 stands of a rolled piece, which showed severe local flatness in cold mill, is simulated. The influence of deviation is studied according to the practical rolling condition and production data.

According to the practical production, the deviation of rolled piece is always within $100 \mathrm{~mm}$, therefore the deviation in simulation is set as $25 \mathrm{~mm}, 50 \mathrm{~mm}, 75 \mathrm{~mm}$ and $100 \mathrm{~mm}$, and the deviation to the operation side as positive direction. Simulation results are shown in Fig.3. The deviation direction is consistent with the side having larger integral area and there is a nearly liner relationship between deviation and profile asymmetry degree. The comparison between simulation results of different stands show that, deviation affect the profile asymmetry degree more at the upstream stand, the reason for which is the rolling force is larger at upstream stand and same deviation causes larger change of rolling force on both sides, thus leading to larger increment of deflection of rollers and forming a significantly asymmetric profile. Taken the transfer effect of strip steel profile between the rolling stands into consideration, the deviation control at the upstream stand is important to improve the profile quality at the exit side of finishing mill.

The width of rolled piece is set as $1350 \mathrm{~mm}, 1650 \mathrm{~mm}$ and $1950 \mathrm{~mm}$ while the other parameters remain unchanged in this simulation. The results, which are shown in Fig.4 indicate that, profile asymmetry degree increases with the width of rolled piece but the increasing extent decreases gradually. The work roller can be regarded as cantilever beam with the rolling central line regarded as cantilever end. Taken rolled piece's deviating to the operation side as an example, the rolling force imposed on the operation side of work roller increase and the rolling force arm is longer when the wider piece is rolled, thus causing the larger deflection of work roller on the operation side, while the contact pressure between rollers concentrate to the operation side, reducing the deflection of work roller. The comprehensive action makes the profile asymmetry degree increase with the width of rolled piece in the form of conic. It also can be derived from Fig.4 that there is a more evident change of profile asymmetry degree with the change of the width of rolled piece when the deviation increases. As the wide and thin rolled piece is inclined to show complex flatness problems, its deviation control rule should be stricter.

\section{Control in production spot}

According to the simulation results, the deviation range of rolled piece is limited within $20 \mathrm{~mm}$. The comparison of profile asymmetry degree of randomly selected 100 rolled pieces after controlling deviation and that of rolled pieces showed flatness deficiency was made and the result is shown in Fig.5, from which it can be seen that after the deviation is limited, profile asymmetry degree of $86 \%$ of rolled piece are less than $2 \mu \mathrm{m}$ and an obvious improvement of profile asymmetry has been made. 


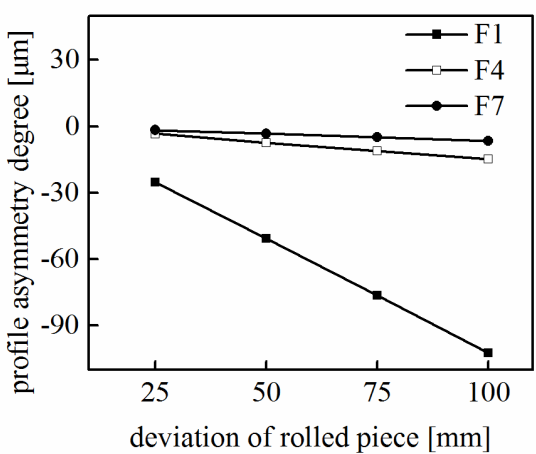

Fig.3. Influence of deviation at different stands

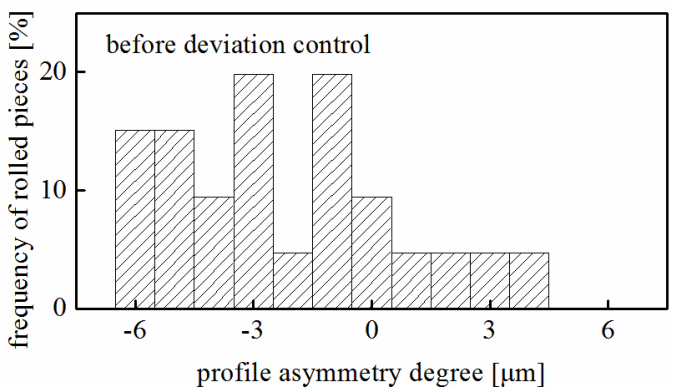

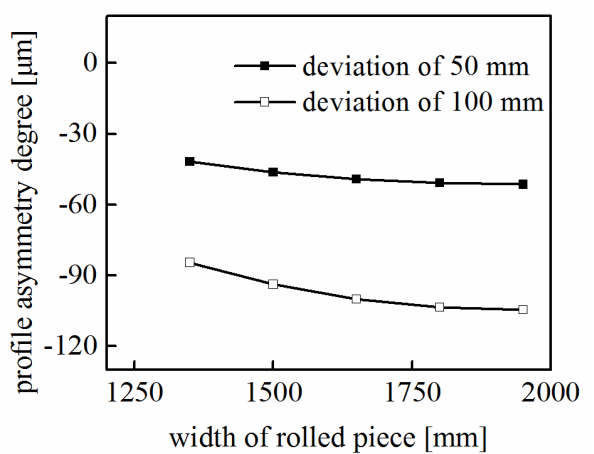

Fig.4. The change of $A_{p}$ with the width of piece

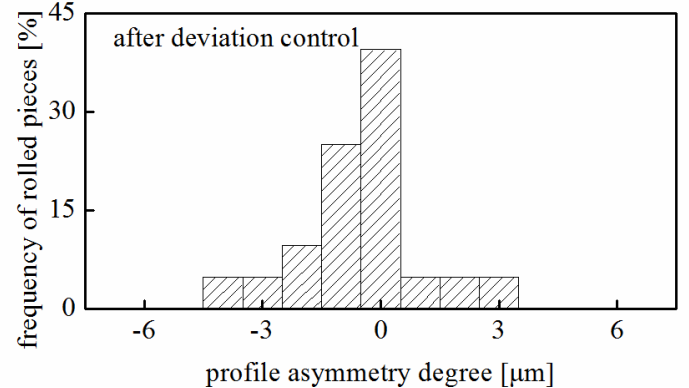

Fig.5. The comparison of asymmetric quality before and after deviation control

\section{Conclusions}

(1) Based on the research on the profile character of rolled piece of a $2250 \mathrm{~mm}$ hot mill, a new index, profile asymmetry degree $A_{p}$ is raised and its relation with the wedge and three-order wedge is determined. Compared to wedge, profile asymmetry degree can fully reflect the profile character in a simpler form.

(2) The simulation is conducted via asymmetric deflection model of rollers built by introducing tilting variables of rollers into the symmetric model based on influence function method. The results show that, the profile asymmetry degree is larger at upstream stand and the profile asymmetry degree increases with the width of rolled piece in the form of conic. The shape quality of rolled pieces has received an obvious improvement after the deviation controlling based on the simulation results.

\section{References}

[1] T. WANG, H. XIAO, T.-Y. ZHAO and X.-D. QI, J Iron Steel Res Int. 19(2012) 14-19.

[2] T. SHIRAISHI, H. IBATA, A. MIZUTA, S. NOMURA, E. YONEDA and K. HIRATA.ISIJ Int. 31 (1991) 583-587.

[3] Y. KANG, Y. JANG, Y. CHOI, D. LEE and S. WON. ISIJ Int. 55(2015) 851-857.

[4] D. BIGGS, S. HARDY and K. BROWN. Ironmaking Steelmaking. 27(2000) 55-62.

[5] X.-C. ZHAO, Y.-L. LIU, Z FU. J Hunan Univ. 7(2011) 37-42.(In Chinese)

[6] J.-N. AOH, H.-K. HSU, W.-T. DAI, C.-Y. LIN and Y.-L. YEH, Numerical simulation on correcting camber and wedge of steel slabs in hot rolling mill, 12th Asia-Pacific Conference on Engineering Plasticity and Its Application, AEPA 2014.

[7] Z.-H. BAI, L.-F. HAN, J.-Z. LI, et al. J Mech Eng. 20(2012) 80-85. (In Chinese)

[8] H.-B. LI, J. ZHANG, J.-G. CAO, et al. J Univ Sci Technol Beijing. 4(2009) 487-491. (In Chinese) 